\title{
Obligaciones en moneda extranjera: el eterno interrogante
}

\section{POR MATÍAS OSCAR MUÑOZ $(*)$}

\begin{abstract}
Sumario: I. Fundamento de las obligaciones en moneda extranjera.II. La cuestión en el Código Civil y Comercial.- III. Los precedentes, la autonomía de la voluntad y el juez legislador.- IV. Propuesta ¿de reforma?- V. Conclusión.- VI. Bibliografía.
\end{abstract}

Resumen: las obligaciones pactadas en moneda extranjera, en particular en dólares estadounidenses, son un asunto reiterado en nuestra legislación, en la doctrina y en la jurisprudencia. La unificación del Código Civil y Comercial, que prevé en su texto expresamente la facultad de cumplir obligaciones contraídas en moneda extranjera mediante su equivalente en moneda de curso legal, ha suscitado una travesía interpretativa según se trate de una norma imperativa o supletoria y en este último caso, renunciable por las partes. Asimismo, en este trabajo se analiza la incidencia del instituto respecto de situaciones en las que existen usuarios de servicios financieros.

Palabras claves: obligaciones - moneda extranjera - autonomía de la voluntad - indexación

\section{Debts in foreing currency: the eternal question}

Abstract: obligations agreed in foreign currency, particularly in US dollars, are a recurring issue in our legislation, doctrine and jurisprudence. The unification of the Civil and Commercial Code, which expressly argues in its text the power to fulfill obligations contracted in foreign currency through its equivalent in local currency, has given rise to an interpretative journey depending on whether it is a mandatory

(*) Abogado. Esp. en Derecho Ambiental y Doctorando por la Universidad de Buenos Aires (UBA). Prof. Adjunto de la Universidad Argentina de la Empresa (UADE). Prof. Adjunto de la Universidad de Ciencias Sociales y Empresariales (UCES). Jefe de Trabajos Prácticos de la Universidad de Buenos Aires (UBA). Investigador del Instituto de Ciencias Sociales y Proyectuales, Universidad Argentina de la Empresa (INSOD-UADE). Investigador del Instituto Lucas Ambrosio Gioja (UBA). Dir. de Proyecto de Investigación, Universidad Argentina de la Empresa (UADE). Miembro de Proyecto de Investigación (UBACYT 2018; Binacional CONICET 2018). Ha publicado contribuciones en revistas de la especialidad, libros y comunicaciones a Congresos y Jornadas. 
or supplementary norm and in the latter case, waivable by the parties. Likewise, this work analyzes the incidence of the institute with respect to situations in which there are users of financial services.

Keywords: debts - foreing currency - party autonomy - indexation

\section{Algunos fundamentos de las obligaciones en moneda extranjera}

El intento por definir el elenco de fundamentos respecto a las obligaciones pactadas en moneda extranjera - si solo es uno- puede parecer, en una primera aproximación, demasiado ambiciosa. En particular, en nuestro país y su estado de normalidad económica, ha resultado un problema recurrente resolver incumplimientos contractuales derivados del desequilibrio en las prestaciones, causado por fenómenos socioeconómicos como la inflación.

Por este motivo, las obligaciones se pactan - entre otras variantes posiblesen moneda extranjera, particularmente en dólares estadounidenses y en distintos contextos negociales. Este trabajo, por supuesto, intentará caracterizar las previsiones que hace al caso el sistema jurídico, más no el abordaje de fenómenos sociológicos en sí, materia alejada del presente.

Ciertas ideas, por cierto, serán necesarias a los efectos de poder dar sentido y alcance al fenómeno en Argentina, la legislación vigente al respecto y los precedentes nacidos al calor del incumplimiento. En efecto, la historia económica argentina demuestra que la previsibilidad contractual en obligaciones a plazo ha sido difícil de cumplir (Muro de Nadal, 1997). En las últimas décadas particularmente, la devaluación de la moneda y las crisis cíclicas han llevado al descalabro contractual y a la necesidad de utilizar herramientas legales estabilizadoras como ser la teoría de la imprevisión(1), incorporada a nuestro sistema mediante ley 17.711 (2).

Pero hoy es un sin sentido analizar aisladamente la cuestión sin hacer referencia frente a aspectos que en un contexto como el de Vélez Sarsfield resultaban impensables: la existencia de relaciones jurídicas de por sí desiguales, como las

(1) Artículo 1198 del Código Civil “(...) En los contratos bilaterales conmutativos y en los unilaterales onerosos y conmutativos de ejecución diferida o continuada, si la prestación a cargo de una de las partes se tornara excesivamente onerosa, por acontecimientos extraordinarios e imprevisibles, la parte perjudicada podrá demandar la resolución del contrato. El mismo principio se aplicará a los contratos aleatorios cuando la excesiva onerosidad se produzca por causas extrañas al riesgo propio del contrato".

(2) Ley 17.711, ADLA XXVIII-B, 1810. 
que ocurren en la contratación consumeril. Por ello es que en el Código Civil hoy derogado no se contemplaba otra cosa que no fuere la contratación libre(3).

En este aspecto, debemos destacar que cuando la obligación pactada en moneda extranjera tenga como antecedente una relación en la que impera el orden público ( $v$.gr. consumidores y usuarios) la cuestión deberá ser analizada desde otra óptica.

Es que en una primera aproximación - y apelando a la autonomía de la voluntad- da la impresión de que, quien se obliga en determinada moneda o a determinada prestación, debe responder lisa y llanamente ante su incumplimiento. En un contexto de inestabilidad como el argentino, ¿Podría alguien asombrarse si el día de mañana el peso argentino se deprecia en un $80 \%$ con respecto a una moneda extrajera por ejemplo el dólar estadounidense?

Pero el asunto no termina allí, porque hacer el silogismo dado que A se obliga con B, ergo A responde ante el incumplimiento, es insuficiente. Tal vez no para la época de Vélez, pero sí para la de una sociedad de consumo donde existen estructuras contractuales diversas y en las que impera la protección de ciertos sujetos débiles jurídicos.

Respecto a estas estructuras sinalagmáticas, el Maestro Carlos Ghersi divisó claramente dos: una estructura contractual por adhesión —-donde el sujeto asiente - y otra, la que el actual código unificado pensó como principio general (lo cual es ampliamente discutible), es decir, el clásico contrato paritario (Ghersi y Weingarten, 2017). Responde - generalmente pero no excluyentemente- a la primera de esas estructuras el derecho de los consumidores y usuarios. Este aspecto es relevante a los efectos de comprender las incógnitas a despejar.

\section{La cuestión en el Código Civil y Comercial de la Nación}

El Código Civil hoy derogado hacia expresa referencia a las obligaciones contraídas en otra moneda que no fuere de curso legal. El asunto en el actual Código unificado presenta algunas dudas interpretativas.

El artículo 617 del Código Civil consideraba a las obligaciones de dar moneda "que no sea de curso legal en la República" como obligaciones de dar sumas

(3) Ilustrativo de la postura del entonces legislador, se interpreta en la nota al artículo 943 del Código Civil en el cual rechazaba la lesión enorme: “(...) Finalmente, dejaríamos de ser responsables de nuestras acciones, si la ley nos permitiera enmendar todos nuestros errores, o todas nuestras imprudencias. El consentimiento libre, prestado sin dolo, error ni violencia y con las solemnidades requeridas por las leyes, debe hacer irrevocables los contratos". 
de dinero. Previo a la modificación que de dicho artículo hizo la ley 23.928 (artículo 11 nota) se eliminó de la redacción original la posibilidad de entregar el equivalente en moneda local y las obligaciones debían cumplirse "en la especie designada", siendo una máxima del derecho obligacional que el deudor cumpla la prestación a la cual se hubiere comprometido (principio de identidad que hace al objeto de la obligación, conf. artículo 725 Civ. y Com.). Por supuesto, la norma comentada se inscribe en el marco de la denominada convertibilidad, considerando que dicho instrumento equiparaba un dólar a un peso, pero no a otras monedas. Dicho dispositivo sobrevivió hasta la reforma operada con la unificación de cuerpos civiles y comerciales.

A su turno, el actual Código Civil y Comercial de la Nación señala en los artículos 765 y 766 que - pese a emplazar a en el título "obligaciones de dar sumas de dinero" - implica, según el último párrafo del artículo 765: “(...) Si por el acto por el que se ha constituido la obligación, se estipuló dar moneda que no sea de curso legal en la República, la obligación debe considerarse como de dar cantidades de cosas y el deudor puede liberarse dando el equivalente en moneda de curso legal" (4).

A su turno, el artículo 766 del mismo cuerpo normativo dice: “(...) El deudor debe entregar la cantidad correspondiente de la especie designada".

Desde un punto interpretativo, las normas no pueden ser consideradas de manera aislada, sino que deben ser integradas en el sistema.

En este sentido, algunos precedentes - a los que haré referencia en el punto a continuación - han interpretado que la "válvula de seguridad", obrante en el artículo 765 in fine, implica una norma meramente dispositiva y no imperativa, y por ello no libera al deudor en supuestos de obligaciones que han sido contraídas en moneda extranjera.

Ahora bien, ¿cuál ha sido el criterio para consagrar dicha norma? y por otra parte $i$ Qué sentido tiene la disposición normativa que permite liberarse en equivalente, si debe ser expresamente pactado por las partes?

En primer lugar, debemos analizar ambas normas a la luz del anteproyecto de unificación, de lo dispuesto en el proyecto modificado por el Poder ejecutivo y -finalmente- de la norma que ha quedado redactada según el Congreso Nacional.

(4) La negrita me pertenece. 
En tal sentido, el anteproyecto de reformas indicaba

ARTÍCULO 765.- Concepto. La obligación es de dar dinero si el deudor debe cierta cantidad de moneda, determinada o determinable, al momento de constitución de la obligación. Si por el acto por el que se ha constituido la obligación, se estipuló dar moneda que no sea de curso legal en la República, la obligación debe considerarse como de dar sumas de dinero.

ARTÍCULO 766.- Obligación del deudor. El deudor debe entregar la cantidad correspondiente de la especie designada, tanto si la moneda tiene curso legal en la República como si no lo tiene.

A su turno, la modificación introducida por el Poder Ejecutivo señalaba (según los fundamentos del texto oficial):

ARTÍCULO 765.- Concepto. La obligación es de dar dinero si el deudor debe cierta cantidad de moneda, determinada o determinable, al momento de constitución de la obligación. Si por el acto por el que se ha constituido la obligación, se estipuló dar moneda que no sea de curso legal en la República, la obligación debe considerarse como de dar cantidades de cosas y el deudor podrá liberarse dando el equivalente en moneda de curso legal, de conformidad con la cotización oficial (5).

ARTÍCULO 766.- Obligación del deudor. El deudor debe entregar la cantidad correspondiente de la especie designada.

Al respecto, tenemos dos visiones contrapuestas, sin variación en lo que respecta al 766 y sin pautas que permitan interpretar o inferir cuál ha sido la finalidad del legislador.

La norma que se aprecia en el anteproyecto (6) parece continuar lo previsto en la Ley de Convertibilidad, mientras que la norma con las modificaciones introducidas por el Poder Ejecutivo implica la liberación por equivalente, pese a la distinción entre el propio proyecto remitido al Congreso y los fundamentos del mismo, en atención a la "cotización oficial", a la cual se calcularía el equivalente.

Esta notable distinción entre valorismo y nominalismo carece de sentido estricto según la interpretación imperante, ya que la norma sería meramente supletoria.

(5) La negrita me pertenece.

(6) Anteproyecto de reformas al Código Civil y Comercial de la Nación, designado por Decreto $191 / 2011$. 
Sin embargo, si es supletoria ¿Es relevante que se encuentre en el Código? ¿Era necesario modificar el anteproyecto? ¿No podrían pactar las partes una obligación alternativa o en su caso facultativa sin necesidad de apelar a dicho dispositivo? Nótese que en las Jornadas Nacionales de Derecho Civil del año 2015 caracterizaron a dicho artículo como obligación facultativa o alternativa (7). Adelanto que comparto la visión mayoritaria en este punto, en tanto y en cuanto - por sus características- el citado artículo implica una obligación facultativa, en la cual el deudor se libera cumpliendo la prestación principal o la accesoria.

\section{Los precedentes, la autonomía de la voluntad y el juez legislador}

La cuestión relativa a la aplicación o no del último párrafo del artículo 765, es decir, la facultad de cumplir por equivalente, no revestía mayor inconveniente cuando un sujeto se obligaba en moneda extranjera, toda vez que con dicho equivalente podía adquirir en el mercado las divisas necesarias para cumplir la prestación prometida.

Sin embargo, un supuesto que podría categorizarse, de acuerdo con el tiempo de celebración de la obligación, de fuerza mayor (hecho del príncipe) modificó sustancialmente la posibilidad: ahora quien quisiera obtener las divisas en el mercado de cambios se vería limitado por el denominado "cepo cambiario" (8). Tal cuestión llevó a considerar en los tribunales el modo en el cual se liberaría el deudor, atento a la imposibilidad fáctica de hacerse de la moneda en el mercado de cambios.

En efecto, la Cámara Civil rechazó en el año 2019 un intento de consignación en pesos respecto de una deuda contraída en dólares estadounidenses. Según el decisorio (9), que, en primer lugar, excluye - y con razón - la aplicación del nuevo Código Civil y Comercial de la Nación, en virtud de encontrarse vigente a la hora de contratar el derogado Código Civil, encontró solución en el propio pacto efectuado entre las partes. Es decir, en el contrato existían normas aplicables para el caso en el cual no se pudiere adquirir la divisa en el mercado de cambios. El propio contrato preveía - incluso- la posibilidad de pago equivalente en pesos, pero con pauta de valor conforme al mercado de Montevideo o de Nueva York, conforme a la cláusula segunda del boleto de compraventa objeto de la litis:

(7) Conclusiones de la Comisión No 2 (p. 2). Recuperado de https://jndcbahiablanca2015.com/ wp-content/uploads/2015/10/CONCLUSIONES-02.pdf [Fecha de consulta: 30/03/2021].

(8) Resolución 3210/2011. Recuperado de http://servicios.infoleg.gob.ar/infolegInternet/anexos/185000-189999/188904/norma.htm

(9) Cámara de Apelaciones en lo Civil, Sala A. Pleus, Santiago Roberto y otro c. Biondo, Luis Alfredo y otro s/ Consignación (26/08/2019). 
Destaco que los demandantes se comprometieron a abonar en dólares estadounidenses el saldo adeudado de U\$S 49.500, lo que fue acordado como una condición esencial e indefectible del contrato (cláusula primera del boleto de compraventa). Como excepción, pactaron que, si por razones jurídicas o de hecho fuese imposible realizar el pago en dólares estadounidenses billete, la parte deudora - es decir Pleus y De Fusco-, a opción de los acreedores, debería hacerlo de la siguiente manera: "a) Entregando la cantidad de Pesos suficientes para adquirir la cantidad de dólares estadounidenses billetes adeudados al valor de tipo de cambio vendedor en los mercados de Montevideo o Nueva York, de acuerdo a lo informado por el diario Ámbito Financiero, El cronista Comercial o cualquier otra publicación a elección de la parte acreedora. b) Entregando a la parte acreedora la cantidad suficiente de Bonos Externos de la República Argentina en cualquiera de sus series vigentes al día de su efectivo pago, para adquirir la cantidad de dólares estadounidenses billetes que corresponda a cada pago en la Ciudad de Montevideo, República Oriental del Uruguay" (cláusula segunda del boleto).

Más allá de esto último, corresponde señalar que - como ya lo ha dicho este tribunal - para que nazca la posibilidad de cumplir la prestación por la vía del equivalente dinerario es preciso que se configure un supuesto de imposibilidad de cumplimiento de la obligación. Es decir que la deudora debe demostrar, si pretende eximirse, que la prestación ha devenido física o jurídicamente imposible, esto es, que existe una imposibilidad sobrevenida, objetiva y absoluta (...).

Desde esta perspectiva, advierto que los demandantes no acreditaron la existencia de una tal imposibilidad, pues, aunque la normativa vigente en ese momento no les permitía adquirir directamente en una entidad financiera la totalidad de las sumas necesarias para cancelar sus obligaciones, sí existían mecanismos (como la adquisición de títulos de la deuda pública y su posterior liquidación en el mercado de valores) por medio de los cuales podrían haberse hecho de la precitada divisa.

Sin perjuicio de esto, reitero, las partes previeron expresamente que, ante la eventual imposibilidad de la deudora de adquirir dólares estadounidenses, esta debía entregar, a opción de la acreedora, la cantidad pesos suficientes para adquirir la cantidad de dólares estadounidenses billetes adeudados al valor de tipo de cambio vendedor en los mercados de Montevideo o Nueva York, o la cantidad suficiente de Bonos Externos de la República Argentina en cualquiera de sus series vigentes al día de su efectivo pago, para adquirir la cantidad 
de dólares estadounidenses billetes que corresponda a cada pago en la Ciudad de Montevideo, República Oriental del Uruguay.

En consecuencia, y atento a lo expresamente acordado por los contratantes, lo cierto es que la imposibilidad alegada por los deudores no se configura en la especie, pues, aun si fuera cierto que no podían adquirir la divisa extranjera ya mencionada, nada le impedía recurrir a la opción en pesos propuesta por los acreedores (10).

Por ende, si bien puede considerarse una directriz, este precedente no arroja aún luz sobre la resolución del supuesto bajo análisis, sino que por el contrario analizó mecanismos alternativos, no contrarios a la norma e incluso previstos en el pacto. Talvez el resultado hubiese diferido ante ausencia de alternativas de cumplimiento contractualmente pactadas.

En una solución más cercana y directamente aplicable, en un caso de adquisición de inmueble en subasta judicial con saldo pendiente, la Cámara de Apelaciones en lo Comercial(11) consideró aplicable el artículo 765, segundo párrafo, respecto del cumplimiento de una subasta inmobiliaria pactada en dólares estadounidenses. Los fundamentos se basaron exclusivamente en la alternativa dispuesta por dicha norma, que considera a tales obligaciones, de dar cosas fungibles. De ese modo, el deudor se liberaba abonando el equivalente en pesos:

Es claro que el principio establecido en el artículo 765 transcripto $s u$ pra da un giro en la cuestión relativa a la naturaleza de la obligación contraída en moneda extranjera con relación a la anterior regulación de la materia, contenida en el artículo 617 del Cód. Civil -luego de su modificación por la ley 23.928-, que establecía que las obligaciones de dar moneda extranjera se regían por las de dar sumas de dinero. El régimen hoy vigente estipula que dicha obligación debe considerarse como de dar cantidades de cosas, mas establece, expresamente, que el deudor puede liberarse dando el equivalente en moneda de curso legal.

En suma, la moneda extranjera como principio no es dinero en nuestro país, sino simple cantidad de cosas fungibles, sin embargo a esa clase de deudas (en moneda extranjera) les resulta aplicable la disposición especial receptada en el Código Civil y Comercial de la Nación, que admite para el deudor la posibilidad de desobligarse dando el equivalente en moneda de curso legal al tiempo del vencimiento de la obligación,

(10) La negrita me pertenece.

(11) Cámara Nacional de Apelaciones en lo Comercial, sala A, "Fideicomiso de Recuperación Crediticia c. Yoma, Emir Fuad y otro s/ Ejecutivo" (19/10/2020). 
siguiendo el criterio general que rige respecto de cosas fungibles, que permite que puedan ser sustituidas por otras equivalentes, a costa del deudor. Es claro que, tratándose de una deuda de "valor", el Código Civil y Comercial de la Nación prevé como expresa solución legal que la valuación de la moneda extranjera puede efectuarse en moneda de curso legal, en términos pecuniarios actuales. Ello, dado que participa de la peculiaridad de las cosas fungibles, respecto de las cuales, como son cosas eminentemente reemplazables, cabe obtener la reposición de igual cantidad, en moneda de curso legal (véase sobre el tema: Llambías Jorge Joaquín, “Tratado de Derecho Civil. Obligaciones", T. II, p. 192 y ss.).

Por último, la Cámara Civil y Comercial de Dolores resolvió un asunto referido al impacto de las restricciones en el acceso a la adquisición de la divisa norteamericana en los siguientes términos:

Ciertamente corresponde abonar en dólares estadounidenses, ni más ni menos en virtud de haber sido pactada en esa moneda la obligación, tal como surge del documento acompañado que ha sido suscripto por el recurrente (v, fs. 299/301), y homologado por resolución del 27/06/2019; sin que aplique al presente supuesto la solución que forzadamente se intenta imponer, toda vez que pretender que el deudor puede liberarse entregando una cantidad de dinero nacional que se exhibe en apariencia equivalente - según el tipo vendedor al cambio oficial - cuando en realidad la entrega de moneda extranjera ha sido considerada esencial en relación con el interés lícito del acreedor (arg. artículo 724 CCiv. y Com.), claramente tal conclusión no luce ajustada a derecho, más bien representaría un desequilibrio prestacional. A propósito, el convenio textualmente reza “(...) siempre en la moneda estadounidense (...)" (12).

En el caso, los demandados debían cumplir una obligación a plazo por USD 500 , en la cual no se había pactado ninguna alternativa para el cumplimiento en otra moneda que no fuera el dólar. Entre ambos, los demandados podían hacerse en el mercado formal de USD 400. El decisorio versó, entonces, sobre cómo cumplir el remanente, es decir, los USD 100 para completar la cuota del caso.

Allí, la Sala E de dicha cámara efectúa el siguiente análisis:

En otras palabras, la cantidad de U\$S 100 que exceden la posibilidad de adquisición será sustituida por una cantidad de moneda de curso

(12) Cámara Civil y Comercial de Dolores, sala E. “Zucatto, María Catalina c/ Lobos, Yanina Marial y otro/a s/ Reivindicación", 07/07/2020. 
legal al valor equivalente al del dólar tipo vendedor que informe el Banco Central de la República el día anterior al del vencimiento de cada cuota con más el $30 \%$; de esa manera quedarán ambas partes en un pie de igualdad en atención a las medidas que sobrevinieron al acuerdo que firmaron (...).

Aunque es posible señalar que al haber puesto un tope del $10 \%$ a la moneda extranjera en el convenio, hace presumir que tanto actor cuanto demandados y sus letrados tuvieron en cuenta la debilidad de nuestro sistema económico financiero y sus consecuencias; por lo que en esta instancia de conformidad con el artículo 960 Cciv. y Com. se modifica tal límite.

Es importante señalar que existen sobre estas obligaciones dos cuestiones muy distintas: la primera, la ocurrencia de restricciones cambiarias, que no permitan acceder a la moneda por la cual el deudor se ha obligado; la segunda, la excesiva onerosidad sobreviniente que pueda llegar a desequilibrar las prestaciones.

Sobre el primero de los supuestos, será cuestión de debate y prueba acreditar que una restricción - como la imperante en nuestro país- es la que impide acceder al mercado de cambios, con la consecuente imposibilidad de cumplimiento. En el segundo supuesto, la cuestión puede presentarse más dificultosa, en virtud de que imprevisión se basa en la imposibilidad de prever determinadas consecuencias por parte del deudor. Así las cosas, la propia historia reciente de nuestro país pone en jaque la idea de imprevisibilidad frente a la devaluación de la moneda (13). Es más, sin perjuicio de interpretar cada obligación conforme a la fuente por la cual ha sido creada, lo cierto es que justamente, quien se obliga en determinada moneda ( $v$.gr. el dólar estadounidense) lo hace con el objeto de no perder poder adquisitivo.

Es entonces menester, según cada caso concreto, considerar si en el supuesto existe un desequilibrio no imputable a las partes, $\mathrm{o}-\mathrm{al}$ menos - no previsible al momento de obligarse.

No obstante lo expuesto, no es menos cierto que debe existir algún grado de previsibilidad respecto a la interpretación de la norma en conflicto. En efecto, si el artículo 765 de lege lata permite liberarse en moneda de curso legal, difícilmente la cuestión tenga que ver con el orden público o el carácter supletorio de la norma, sino con que las partes hayan o no previsto alternativas ante la imposibilidad de

(13) Tal fue el caso del colapso del año 2001, situación en la cual se emitió el decreto de necesidad y urgencia No 214/2002 por el cual las obligaciones contraídas en dólares quedaban —mediante dicho decreto- transformadas a pesos argentinos. 
incumplimiento. Para el caso, muchos de los contratos actuales prevén expresamente la renuncia al supuesto del artículo 765 in fine.

\section{Propuestas $\underset{i}{ }$ de reforma?}

La idea de reformar o no un artículo como el bajo examen plantea evidentes dudas. Las mismas dudas que plantea el futuro de la moneda de curso legal.

En tal sentido, esta cuestión puede considerarse en Argentina como un problema netamente local, cuando en ejemplos comparados se encuentran supuestos de veda al pacto en moneda extranjera (14).

La idea del anteproyecto de reformas se basaba en que el deudor cumpla aquello a lo que se ha obligado, basado en buena medida en el denominado principio de identidad (y por qué no de integridad) que rige el objeto de las obligaciones. Se supone que, en tal supuesto, quien se vincula en dicha moneda es responsable de cumplir en tal especie. La válvula de seguridad quedaría amparada en las reglas generales contractuales y obligacionales, en caso de imposibilidad de cumplimiento.

Nada obsta, por supuesto, a que las partes planteen —ahora sí, en el marco de la autonomía de la voluntad-distintos escenarios, como el caso en el cual se establecen obligaciones alternativas o bien facultativas (mucho más probable las de este último tipo).

Por otro lado, ¿cuál sería la justicia del equivalente? ¿La cotización oficial? ¿Con tributos o sin ellos? ¿Quién justificaría tal elección en caso de vacío contractual?

Otra cuestión muy diversa resulta aquellas obligaciones en las cuales exista un débil jurídico como lo es el consumidor o usuario. Entiendo que allí el tratamiento referido a la autonomía de la voluntad se ve recortado, o al menos tiene otros reparos que una relación paritaria.

Es que, en supuestos en los cuales se ve involucrado un consumidor, resulta aplicable el estatuto del consumidor y con él una serie de normas tuitivas al respecto. En este aspecto, no es lo mismo la libertad de relaciones entre iguales, que aquellas en las cuales existe desequilibrios propios de la relación, como es en el segundo caso. En ese sentido, mucho se ha debatido respecto del denominado consumidor o usuario de servicios financieros, toda vez que allí habrá que analizar supuestos que hacen a dicha relación, en la cual impera el orden público. Se

(14) Tal es el caso de Brasil, que, muy por el contrario, tiene vedada la posibilidad de contraer deudas en otra moneda que no sea el Real, tal como cita — entre otros-Calvo Costa (2019). 
equivoca - en este supuesto- cierta doctrina que interpreta que, como en el caso no puede considerarse abusiva ninguna cláusula respecto del precio, no sería procedente el carácter imperativo del artículo 765 (Calvo Costa, 2019). En tal sentido, podrían existir cláusulas abusivas que no hagan en sí al precio sino a la prestación y - por ejemplo- a renuncias (como abdicar a la aplicación del artículo 765 CCiv. y Com.), tal como se ha señalado al respecto (Chamatrópulos, 2019). Recordemos que, en nuestro derecho, la obligación en moneda extranjera debe considerarse como obligación de dar cantidad de cosas. Otra interpretación, sin perjuicio de lo dispuesto en el artículo 1121 inc. a), iría en contra del carácter protector del derecho del consumidor. En el mismo sentido, no podemos interpretar el reiterado artículo 765 de manera integradora y una norma tuitiva, no.

En conclusión, la disposición contenida en el artículo 765 es renunciable - de manera expresa - con limitaciones para el supuesto de usuarios de servicios financieros.

\section{Conclusión}

A modo de conclusión, puede señalarse que el comentado artículo 765 del actual Código Civil y Comercial de la Nación ha traído consigo mayor incertidumbre respecto a los supuestos en los cuales se debe cumplir obligaciones en moneda extranjera.

Los términos en los que ha quedado redactada la norma - sin perjuicio de lo señalado en el supuesto del artículo siguiente a dicho precepto-implica que quien se obliga en moneda extranjera, como ser corrientemente el dólar estadounidense, puede a su turno liberarse mediante el equivalente en moneda de curso legal ( $v . g r$. pesos argentinos) excepto que expresamente se haya renunciado a tal facultad legal.

Otra interpretación posible radicaría en que no se trata de una norma imperativa o de orden público, sino meramente supletoria y por ello el deudor no podría imponer el pago en su carácter de solvens excepto que así lo hayan pactado las partes. Respecto a esta segunda línea interpretativa y ante el silencio ocurrido entre el anteproyecto de reformas, el proyecto del poder ejecutivo y la norma hoy vigente, solo puede entenderse que el legislador ha querido consagrar explícitamente la facultad de liberarse mediante el equivalente. No entiendo en este aspecto que estemos frente a una regla de aplicación supletoria, como indica parte de la doctrina (Calvo Costa, 2019; Rivera, 2020). Nótese en ese sentido que, de las propias conclusiones de las Jornadas Nacionales de Derecho Civil de 2015, no surge una inequívoca postura respecto a la interpretación del precepto (15).

(15) Ver nota 6. 
Esto último también engendra un problema, porque el acreedor tiene una expectativa de cumplimiento, que es la moneda prometida y no otra.

Por ello, resulta relevante considerar dos aspectos: por un lado, si existe una restricción sobreviniente a la adquisición de la divisa en el mercado de cambios o bien si existe un verdadero desequilibrio en las prestaciones que sea considerado imprevisible.

Pero más allá de la decisión jurisdiccional que en última instancia será la que decida la suerte de las partes, es relevante procurar una redacción clara en la norma. Si existen distintos sentidos interpretativos frente a un mismo precepto, claramente la cuestión no ha sido zanjada. En esta línea argumentativa, es forzado interpretar que la norma es meramente dispositiva si aparece (incluso contrastándola con el anteproyecto de unificación del Código Civil y Comercial) como una facultad legal a la cual el deudor puede echar mano. En esa misma idea, debe contemplarse la situación en la cual exista una relación de consumo, toda vez que allí la autonomía de la voluntad se ve recortada por los principios tuitivos y protectorios de tal vínculo jurídico, como en el caso de una renuncia a algún derecho de dicho catálogo.

\section{Bibliografía}

Abatti, E. y Rocca, I. (2021). Moneda extranjera. Saldo de precio en compraventa inmobiliaria por subasta judicial. ¿Esfuerzo compartido? La Ley, 17/02/2021, 9. AR/DOC/3745/2020. Buenos Aires: La Ley.

Alterini, A.; Ameal, O. y López Cabana, R. (2008). Derecho de Obligaciones. Buenos Aires: Editorial Abeledo Perrot.

Azar, A. y Mancini, M. P. (2020). La moneda sin curso legal como objeto esencial de las obligaciones de dar. La Ley, 01/10/2020, 8. AR/DOC/3165/2020. Buenos Aires: La Ley.

Calvo Costa, C. (2019). Derecho de las obligaciones. Buenos Aires. Editorial: Hammurabi.

Chamatropulos, D. (2019). Control de cláusulas abusivas en la coyuntura: precios, inflación y contratación en moneda extranjera. La Ley, 20/11/2019, 1 (p. 784). AR/DOC/3567/2019. Buenos Aires: La Ley.

Ferreyra Romea, S. (2017). Obligaciones de dar sumas de dinero en moneda extranjera. Un instituto que se mueve al compás de la economía argentina y que 
no está exento de desafíos con el nuevo Código Civil y Comercial. $R C C y C 2017$ (diciembre). 139 AR/DOC/2802/2017.

Ghersi, C. y Weingarten, C. (2017). Manual de Contratos Civiles, Comerciales y de Consumo. Buenos Aires: La Ley.

Manfredi, L. (2020). Teoría del esfuerzo compartido. Aplicación al desajuste prestacional sobrevenido en un contrato de locación inmobiliaria con destino comercial con cláusula de pago en moneda de curso legal, en la cantidad necesaria para adquirir moneda extranjera. $R C C y C 2020$ (diciembre), 208. AR/ DOC/3590/2020.

Mazzinghi, M. y Mazzinghi, S. (2020). La cancelación de obligaciones en moneda extranjera a la luz de la reciente jurisprudencia. La Ley, 16/11/2020, 8, AR/ DOC/3746/2020.

Muro de Nadal, M. (1997). 50 años de historia económica argentina 1946-1996. Una sintesis de sus principales características. Buenos Aires: Sauce Grande S.A. Editores.

Paolantonio, M. (2020). Obligaciones en moneda extranjera: jurisprudencia anotada y panorama actual. $R C C y C 2020$ (noviembre), 188. AR/DOC/3093/2020.

Parellada, C. (2020). El derecho y la economía. Sus desencuentros en las obligaciones de dar moneda extranjera. La Ley, 16/11/2020, 3. AR/DOC/3767/2020.

Rivera, J. C. (2020). Cumplimiento de obligaciones en moneda extranjera: la Babel de los tiempos que corren. La Ley, 2020-F, 343. AR/DOC/3691/2020.

Fecha de recepción: 30-03-2021 Fecha de aceptación: 22-07-2021 